\title{
"Openings:"
}

\section{A Political Movement in Lebanon? A Conversation on Feminism and Queerness}

\section{Sanaa H.}

"Openings" is a corner in Kohl that aims at presenting a collective experience in thinking and writing, through publishing excerpts of recorded discussion sessions among those who work in a particular field or topic, or people who are interested in it. The discussions take place in the presence of a mediator who directs the debate then extracts the main ideas to write them and publish them in a summarized article.

"Openings" aims at showing and exposing different and even opposing points of view and opinions, and opening the floor for the expression of a large number of people who have valuable experiences and opinions, and who do not have the time or the will to write.

"Openings" intends to challenge the traditional methods of knowledge production, especially within academic circles that are often characterized by exclusivity, individuality, selectivity, and complex requirements.

It also hopes to expose and activate the intellectual wealth that characterizes the discussions and collective thinking, and then to incorporate the public audience in the suggested issues. This experience combines journalism and public discussions by tackling subjects that are usually categorized as academic or "elitist." This way, "Openings" allows for the revaluation of writing, publishing, and representation politics, and encourages those who participate to exchange their experiences and their ideas and to develop them openly and publically. This article constitutes the first attempt at "Openings," and will be followed by other articles that allow its development and the refining of its technical aspect, its chosen topics, the characteristics of those who participate in it, and the methods of writing, publishing, and drafting. 


\section{Introduction}

In the first part, "Openings" hosted five queer feminist participators who worked and/ or are still working together in various queer feminist fields, among which are support and solidarity groups, civil and community associations, and non-governmental organizations. The relationship between these women dates back to 2008 and 2009, and they have political, professional, and personal relationships. These bonds underwent different stages, which included periods of proximity and distance, agreement and disagreement, for many reasons, the most important of which were related to political and organizational disparities within the communities and groups where they worked together. The mentioned participators live in Beirut and have various jobs within different fields, such as political and social work, advocacy, teaching, research, and movie-making, and their ages vary between 25 and 35 .

In this part, "Openings" addresses the concept of the "political movement" in Lebanon according to the participators, and their reading of its meanings, its manifestations, and its realities today. The discussion involves an attempt to define the "political movement" and its numerous crises, and the experiences of the participators in different queer feminist frameworks, the value of a collective political organization in the Lebanese context, and the personal and social relationships that form miniature political communities. The first discussion session was held in the house of a participator on the 10 $10^{\text {th }}$ of May 2015 for two and a half hours. A second discussion session followed on the $24^{\text {th }}$ of May 2015 for two hours, during which the participators continued their detailed debate about political work within queer, homosexual, and feminist groups and associations in Lebanon. This article includes short excerpts of the main ideas that occurred during the first discussion session only.

When it comes to representation policies, it should be mentioned that the participators are speaking out of their personal experiences and opinions, and they, therefore, do not represent any side or group or association, and are only expressing their own views, even when they speak in plural.

Pseudonyms were used in this discussion to protect the privacy and safety of the participators.

If you would like to suggest an idea for discussion, or even host a discussion with a particular group of people in the "Openings" corner, you may contact the Kohl team at: kohl@gsrc-mena.org 
Sanaa: What does "political movement" mean to you? How do you define it?

Ghenwa: I see it as fragmented now, meaning lacking of intersectionality. We have been been fragmented and divided a lot. At first there was the gay community, then there was a lesbian community, then the queer community, then the transgender community, then the feminist community. There is a real division. There is also a division between those who want a political struggle and those who want an apolitical struggle. I do not think there is a common goal.

Sanaa: $\quad$ But if we were to speak of the "political movement" on a theoretical level, prior to any practice, what does this "movement" mean to you?

Ghenwa: It means collectivity, or a group of people regardless how academia defines a "community" or a "group." For me, it means a group of people who share a common goal, who understand the weaknesses and strengths of one another, who complete each other without the existence of hierarchy. The movement is an integrative action. I find that the movement is constituted of many coalitions, thousands of clusters.

Sanaa: What brings together these clusters and what connects them to one another? I agree with you that coalitions build a certain movement, and the movement should not necessarily be constituted of a group of people who are perfectly similar or in agreement. It is made of various coalitions that differ in effectiveness and duration, but that are all effective in some way, and capable of producing a movement. For example, many groups, one of which was the "toppling of the sectarian regime." shared a common goal theoretically, and might have been formed of people and groups that were similar and in harmony to some extent. However, despite that, they faced many setbacks, like the joining of sectarian parties, and they did not last. So, what do these alliances, or coalitions as Ghenwa called them, share, if it wasn't the stated goal or the inner harmony among them?

Jo: $\quad$ There might be one common stated goal, and some kind of agreement, but it seems there might be fragmentation in the practical implementation of the goal, or maybe different people might want to achieve different outcomes under that common goal.

Ghenwa: Exactly. But the intersectionality might mean that each person has their own focal point, around which revolves their political thought and their aspirations in the coalitions.

Jo: $\quad$ So the "movement" should overcome the limits of identity politics. I mean any movement should take into account the possible differences in the identity politics of its members, without making these identities one of its goals. 
We saw the rise of movements that gave themselves goals that were known as "comprehensive," "national," "big," and "inclusive" goals for different identities and affiliations, such as the campaign for "toppling the sectarian regime," and that worked, at least in their public speech, on the temporary use of identities. Why were they unable to continue in your opinions? Maybe it is not necessary for a political movement to be built on one goal, because the goal might be theoretical, or not applicable, or too large so that it can include everyone but stops being realistic. Or the movement's coalition might not be actual or important, or it might face conflicts, which would lead to the inability or the failure of the movement that is based on that goal. This is the first challenge, and there is the challenge of intersectionality that puts us in alliances and in opposition with people, such as being in alliance on the issue of resisting Israel, but at the same time, fundamentally opposing the religious nature and the sectarian, foreign, and economic agendas of the active forces of resistance. So, if the unity of the goal is not the essence of the political movement, and if intersectionality is not the solution either, what does "political movement" mean? And how is it constructed? Maybe we can think based on our experience in feminist and queer circles.

Qid: $\quad$ Honestly, I do not see a political movement in Meem or in Nasawiya. Actually, the only action that I called movement, was the campaign for "toppling the sectarian regime" because it was the only one in which I felt I might find my mother walking in. The criterion for me was always: Does my mother participate in this movement? My problem with the "secular march", or even with Nasawiya or Meem or Helem, is that their speech only addressed a certain class and enforced particular class criteria asking people to "rise" to them. To me, and to everyone from a particular background, where we do not use any English words at home for example, I had to keep up with the requirements and the lifestyle of the middle and upper-middle class even, to find myself a place in what is called a "political movement." I needed time to come to this class analysis. I feel that we had particular demands, but we did not have a political movement. I feel hurt when some of us link the fate of the political movement to the end of Nasawiya or Meem for example, because then it makes revolve around us only. As if the movement only started with us, and there was no change or political discourse before us. Maybe this is why we all felt deep mourning when the group ended. Intersectionality exists for us in thought, but actually, we are disconnected from reality. We live in a bubble. We talk a lot about connecting struggles and their intersection as individuals, and maybe in our private and individual politics, but in our collective politics, we did not really translate this intersectionality.

Lynn: It was a common belief that Meem builds a community and Nasawiya builds a movement. You enter Meem and, suddenly, it is as if you entered a certain factory that turns you into a feminist activist. If you needed a psychological consultation about your sexuality, okay, Meem will provide it to you. But consequently, you have to become an activist, or you would be kind of marginalized. Even the strategies Meem included: The 
first step, building a community, the second step, building a movement, without the mention that there was no movement before Meem, but with the focus of its uniqueness and exceptionalism. The movements that came before Meem were women's rights movements and non-governmental organizations (NGO). We lived in an illusion that we are different from NGOs. We saw our work as politicized, as inclusive, and we believed in changing the world. We sometimes felt that there were some problems, but we all believed that change is happening and that we are leading the movement. We succeeded at creating an effective noise sometimes, in Lebanon and even in the region, and we were also known in some international mediums, but we were not working by the values we pretended to have, such as being a place relying on self-funding. I think we wanted to have our own ways and style of life, but the reality was not so. We were working within a certain hierarchy, even if it was invisible, and we were getting funding.

Sanaa: $\quad$ And we would write reports...

Lynn: $\quad$ Yes. Also, I discovered with time that in Meem we do not all share the same goals, and we do not work in the same way. It was the opposite. Maybe there were different movements and not one movement, or maybe we were the sparks towards some movement. There were ideas that excited us, that we worked for, and then they burnt out. Our work was not structured and focused. Also, we were building ourselves in opposition to others, or as a reaction to each other or to others.

Ghenwa: $\quad$ To comment on that, I think some circumstances worked against us. We started working in the context of NGO-isation after 2000, and funding and donations, so it was easy for us to end up like others. But I think the reason why we failed is that we did not take risk with ourselves or our bodies, we did not go out to the streets and we did not vandalize. We were a comfortable movement leading a comfortable, safe struggle. Maybe the decisive moments were when we went out and were present in public with our queer bodies. I have great respect to the teachers' syndicate, because they had a cause, and a lot of anger and energy. Their cause meant life or death and they had no choice. But us, we were nice feminist activists within the accepted framework.

Sanaa: I do not want to justify our behavior, but I do not encourage self-whipping. We were young and our group did not have the history or the roots of the teachers' syndicate. There is no basis for comparison here.

Ghenwa: $\quad$ The teachers' syndicate came out of an urgent need.

Qid: $\quad$ Intersectionality was part of it. 

intersectionality in the struggle of the teachers' syndicate. I am afraid, here, of the romanticization of labor struggles as intersectional when that is not the reality.

Qid: $\quad$ Why?

Sanaa: We did not see it in any of the protests for the passing of the bill for the protection of women from domestic abuse for example, and it is almost impossible to find this syndicate working on gender issues for example... And it did not take a decisive position, or at least a public one, with regards to the right to education of Syrian, Iraqi or others refugees.

Lynn: $\quad$ Or sex education at school for example...

Sanaa: I do not think that need alone creates a radical political movement. There are other natural circumstances like the passing of time, the accumulation of experience, and the appropriate political situation in which the confrontation matures. And going back to Meem, it was necessary for it to exist, otherwise it would not have. This need was the confrontation and the resistance of the everyday oppression we were living and still live under as individuals and groups who are queer in gender and sexuality. It was also not only a space to discuss the problems relating to our sexual identities and our lives, but also our class problems, our familial problems and so on. Meem was a political and a politicized place. And maybe what gave Meem a particular identity was the absence of a traditional written goal that characterizes the work of associations and movements. And despite that, we never failed to support human rights legal organizing, like the bill for the protection of women from domestic abuse, in spite of the critiques some of us had about it, and we were ready to go on a hunger strike to pressure for its passing. Maybe radical acts come from particular tactical goals? But I want to back to what Lynn said earlier and ask: Why do we criticize ourselves for wanting to build a community for ourselves? Do we see in it a contradiction with building a political movement?

Alissar: $\quad$ Honestly, I was annoyed with the statement that we failed, and I have a different point of view, because I believe that we did wonderful work. The movement in Lebanon started over the Internet with Gay Lebanon and Lesbanon and other chat channels and mailing lists, then we started to move to more public places, and people started meeting up in parties and get-togethers in club free and Helem, which later did important movements on the ground such as the protest in Sodeco, when some guys assaulted two young men and beat them. These movements pushed people to talk more about sexual issues. I think the movement should have a clear and defined goal, or else it becomes unrealistic, like the campaign for toppling the sectarian regime. And when it comes to the abolishment of Article 534, or the increase of acceptance and respect or the encouragement of debating sexuality for example, I see these as realistic and achievable 
goals, especially in the last 15 years, with all the changes in the country. I also think that Meem was a political movement, because it created people who are skilled in many fields, and who are from diverse backgrounds, and it brought them together. Look at all we have exchanged and learned from each other, and all that we have accomplished. Bekhsoos is widespread internationally. So is Bareed Mista3jil. Meem has had real influence, and we cannot say that it was not a political movement. In short, change happens all the time, but it happens at a slow pace. Let's compare nowadays with the year 2000 , and we would see the development that took place.

Jo:

I'm finding it hard to define a movement. Obviously there was something happening before we came into the picture and became active around certain issues. We, for example, had a problem with the politics and the ways that women's rights organizations before us worked, even though these organizations were doing the actual work on the ground. I remember that we struggled a lot to ally ourselves with these organizations, because we had this idea that we did not want to become like them. It was difficult for us to see them as allies. It took time for us to decide to work with them and support their projects. But what connects the parts of a movement together, because it's obviously not the goal, or at least the goal isn't enough? Is it the people themselves?

Lynn: I want to answer to the idea of building a community. Recently, I started to think about my previous position on this issue, and I started noticing that I may have, during some period of time, become obsessed with building a political project that we would all agree on and work to accomplish, to the point where I underestimated the importance of building a community. But today, I think, it may be impossible to build a movement without building a community for it. Even if I think of my personal life, my closest friends are people I met in Meem. They are among the closest to me and we share a rare intimacy. That's an important fact, because we may disagree politically or our political project may collapse, but something would remain. That is where the importance lies.

Qid: $\quad$ For me, this community was built organically. Meem never abided by the decisions of meetings or the documents that were produced through them. And still, we succeeded many times at accomplishing what we were aspiring to, even if we did not mean to. There was a sort of discourse and work and political awareness, we were a politicized community. It has always been and still is, and I do not think it will fade with time.

Ghenwa: The formation of cliques was not necessarily the result of a certain power hierarchy. Sometimes, it was an organic product. I feel that I am part of a movement with you, and with others surrounding me. For example, I feel safe to know that many of you live around my home or in my neighbourhood. We exchange support and services, and we now think of planting our own vegetables. This is the community that I want to be part of, and I feel that these little actions allow us to fight the capitalist system, and that is 
where intersectionality starts for me. It might seem selfish because it is on a small scale, but that is the community I aim for. I do not want more than that.

Sanaa: $\quad$ Of course this doesn't mean that this desired community is not political, because in it and through it we see a lot of internal and external politics. This kind of community is a real feminist political act that feminist women, queers and trans* people can achieve. And it naturally affects society at large, while conserving its own singularity and a certain level of internal independence. But, if we do have this organic community, what is the problem with working consciously and actively to politicize it? Do you see a problem with that?

Lynn: I do not see a problem with that. I do see a problem with conferences and with global and international spaces. And I do see a problem with "preaching" to build a similar community among different groups and in different contexts, like in Kuwait, for example, or in Mantiqitna Qamb, as if there is a preconceived model to build a community or a movement. I find it problematic when we try to "organize" lesbians and queers along the same lines of what we, with our unique personal experiences, did here through presenting a power point of 12 steps to build a community or a support group! These practices could be harmful and counterproductive.

Qid: $\quad$ And one way of preaching is to impose certain behaviors on people who have recently joined the group, like saying that you have to do so and so to be part of the movement.

Jo: $\quad$ Maybe the community that Ghenwa is talking about is the beginning of something. But I still wonder: what brings us together? Is it the respect we have for each other? The values we share? Our approach to life? The comfort we feel amongst each other? What makes Ghenwa say: "this is my community?" Why did this happen to us?

Lynn: $\quad$ Maybe what brings us together is our struggle to live a kind of alternative lifestyle, despite our different ways and lives and struggles. But we are always able to understand each other and to feel a certain connection among our lives and experiences, even if they are not the same. I feel this very strongly in the support that I get. For example, to be able to move from my parents' house to my own home, I stayed at Qid's house for about ten days in order to get used to it. We support each other, and we understand each other, and we show each other different ways of life. All that is very important.

Alissar: $\quad$ But relationships go through good and bad periods, especially within a political movement. For instance, in this particular circle, our relationships with each other have transformed. So let's think a little bit about trust. If there is a problem between the members of a group who have a specific strategic goal in common, and a rift happened among them, does the trust needed for political work continue? Can people who do not trust each other build a movement? Can they work together? 
Ghenwa: $\quad$ For me, trust is everything.

Sanaa: Let's rephrase the question. Can we consider our community, which is built on friendships, personal relations and trust, a politically active community?

Ghenwa: The question is, what kind of politics do you mean?

Sanaa: $\quad$ For me, feminists coming together is a political act. At first, defining oneself as a feminist, and secondly, exchanging support and solidarity on all levels, are also political acts. Plus, engaging in discussions as self-conscious political identities, and articulating this consciousness openly, is a political act. But for you, is our community politicized, and how so?

Qid: $\quad$ From the increase in number of scooters!

Lynn: $\quad$ You taught half the neighborhood how to ride a scooter! [Everybody laughs]

Jo: $\quad$ Our community is political in how it breaks the rules and norms, and how it defies the system. For example, Ghenwa talked about a social exchange system that overrides the monetary currency and focuses on human relationships. Creating this alternative to the capitalist system is a political act. And as Qid said, the presence of queer bodies and women using motorcycles in public spaces is a political act against a patriarchal system that is always expelling us from the public sphere and is threatening our security; a patriarchal system that is only safe and secure for a certain type of men.

Sanaa: I think what brings us and keeps us together is our constant hope of building a political movement. We are a community and we come to each other a lot of the times, to work on things related to Meem. It is not only community that keeps the movement going. It is also the movement that keeps the community going and cohesive. So now we are talking about two levels of politics, the first is the small political and grassroots community, and it is usually unorganized; and the other is a larger political movement built on strategic alliances and not tactical goals, and it is usually organized and structured. Although it also maintains a more spontaneous grassroots aspect, such as Marsa and Kafa, who are part of this coalition. But the question is, is it enough to have small, unorganized and politicized groups? When does the need for conscious purposeful political organizing come?

Alissar: I I want to add something. I talked about what I called "the history of the movement" based on what I saw and lived when I was 18 or 19. But we do not know what was there before, so we may be an extension of a movement that we are not familiar with. 
You know, my dad tells me that during the civil war and after, there was a punk scene in Jeitaoui, and it included all those people who go out with their chickens and walk the streets with them.

Alissar: $\quad$ Really?

Ghenwa: $\quad$ Yes, they used to tie their chickens and rooster with a rope and walk around with them. He also told me about hippies and how their hair used to look. People used to call them "foufous" and they used to target them because they were pacifists and did not want to participate in the war. They were alternative bodies, not necessarily in the queer sense that we know today, but every period has its queerness. So maybe we really are an extension of an alternative movement from the past.

Alissar: What is considered queer today, and what will be considered queer in five years?

Sanaa: $\quad$ Of course alternative bodies and spaces have their own political specificity, but to what extent do we need a conscious-and intentional, political organizing, in order to be effective?

Lynn: $\quad$ Organizing for what purpose? Personally, at the moment I feel a kind of paralysis primarily because of the general political situation. Look at what's happening in this country, on the borders with Syria and occupied Palestine, and in Syria and Egypt. If we do organize ourselves, what will we do? Based on what causes? How will our struggle on issues of sexuality, for example, look like, in a context that is changing very fast, and where the future does not look clear or simple? Priorities have changed. When we started Meem, maybe that was a priority in Lebanon. Today I do not know what the priority is. Honestly, I do not know what the needs are. Are they connected to this larger political reality? And how? We have to take all these questions into consideration. We cannot organize like we organized in Meem and Nasawiya, because it will be completely irrelevant.

Sanaa: $\quad$ Who do you mean by this "we"?

Lynn: $\quad$ Those of us who have worked together for years. And maybe new people. Queers. Feminists.

Sanaa: $\quad$ But can we not do anything, especially in this political situation?

Lynn: $\quad$ On the contrary. It is especially important to do something. But I feel a kind of disablement. I don't know how to begin, and with what. What we achieved in the past was great and it changed my life, but it was also damaging to me. I need to breathe, to think to myself and about what is going on around me. How did I live these experiences? 
I need to meditate and think about the roles I played and the effects they had. And how I would want my future interventions to look like.

Qid:

What scared me in the issue of starting a new collective was thinking about the people who will work in it and who will come to it. I think of creating space for future generations and how that will look like. We have known each other for a long time, we know each other's language and ways. But how do we open space for new blood into feminist and queer activism? A lot has changed, so I do not feel excited to start a new group, but I would love and I need a space like this one, where we can get together and interact and have discussions.

Ghenwa: I totally agree.

Jo:

I agree with Lynn. I feel that I need a break, to take a step back and think. At the same time, I feel like I need to do something, but I feel like my hands are tied. So to counter this, I feel like I need to do something. Maybe meeting you and having these discussions is something or prepares for something in the future. But there are people who want to do something. Maybe we do not know them, or we do not see them, but they are trying, and they are working. Maybe there doesn't have to be organizing on a larger scale. Maybe a spark can produce a radical change. Look at Baltimore, and Ferguson before that. Rage was building up over the years. And it suddenly exploded all at once. I don't know.

Alissar: $\quad$ But the situation is different. Baltimore lived through centuries of slavery and discrimination and racial oppression.

Qid: $\quad$ The history of the Black political movements is different.

Jo: $\quad$ But if we think about ourselves, what is our tipping point?

Alissar: I look at this in a realistic way. I think there is a political movement over time, and it worked and it was active in certain things, like in legislations or changing public opinions or creating somewhat safe spaces.

Sanaa: $\quad$ But a lot of these changes and developments only serves and has served a specific group, like the middle class that was able to reach privileges such as the internet and to get its voice heard and to express itself and make use of these services. That doesn't mean that what happened was not important, but we have to be critical and to think about its influence and its limitations.

Lynn: $\quad$ For me, the movement is a large scale practice that carries radical changes for a mass of people, especially for those who are most marginalized. We can aim for a radical 
change, and work for it, even if it is slowly, and as you said, the accumulation can lead to radical change.

Sanaa: Ok, one last question, do you believe that there is a political feminist and queer movement in Lebanon?

Ghenwa: $\quad$ Yes.

Jo: I think we were doing things based on certain identities. We held onto these identities and we pursued a plan with them, either to change the general discourse, or to amend certain laws, or to create visibility for issues that matter to us, or to build alliances... We also worked at some point on the idea of "infiltration" to bring up a feminist and queer discourse within different organizations and institutions, and to get our voices heard in these meetings and spaces. There were things happening within these queer feminist notions and expressions. Was it was a movement, actions, or practices? I don't know. But there was something happening there. This discussion is making me rethink what a movement means.

Lynn: $\quad$ I don't think there was a feminist-queer movement.

Qid: $\quad$ I don't know if I see it as a movement or not.

Lynn: In my opinion, there was an effort to build a movement, but we built a community of queer women and trans* people and feminists and all that. And it was an alternative community to a certain extent. But if we want to talk about a movement, we have to think of our coalitions and our relations with other groups and issues, and I don't think we succeeded in that. We did gain a certain "legitimacy" in the eyes of these organizations, when its members saw that we can mobilize people during demonstrations at a time when they could only mobilize ten people in their demonstrations. That is when these organizations wanted us to join them. But have they ever talked about queer issues? About queer lives? Our issues were silenced in their meetings, even when we were present. That is why I don't think we were able to create a large scale political work, or to mobilize other groups around us and next to us. We pretended to be infiltrating their meetings, but we would act like them when we were around them. We would be quiet a lot of the times, and that was a big problem.

Jo: $\quad$ Not everyone, Lynn.

Lynn: $\quad$ Maybe not everyone, but there was a "modification" in our discourse when we met with them. We would lower our tone, so to speak. And we did not get any gains in return. For example, in passing the law to protect women from family violence, we supported and 
we attended and we worked, but there was nothing there for queer women. There was no genuine collaboration to bring other causes to the table.

Sanaa: $\quad$ So there was no strategic coalitions.

Lynn: $\quad$ There were tactical acts, in some instances we felt that we were part of the discourse and issues of these organizations, but there was never any real coalition.

Sanaa: $\quad$ There is a lot to discuss still, and to continue this discussion, we have to go into the details of the political queer and LGBT and feminist organizations in Lebanon.

*The End* 